\title{
Felicola subrostratus parasitando gatos domésticos de São Luís, Maranhão, Brasil: relato de caso
}

\author{
Mayra A. P. Figueiredo ${ }^{1 *}$ \\ Wilson G. Manrique ${ }^{1}$ \\ Rita M. S. N. C. Guerra ${ }^{2}$ \\ ${ }^{1}$ Universidade Estadual Paulista \\ Departamento de Patologia Veterinária, Faculdade de Ciências Agrárias e Veterinárias \\ Via de Acesso Prof. Paulo Donato Castellane, s/n, CEP 14884-900, Jaboticabal - SP, Brasil \\ ${ }^{2}$ Universidade Estadual do Maranhão \\ Departamento de Clínica e Cirurgia, Curso de Medicina Veterinária \\ Cidade Universitária Paulo VI, Caixa Postal 09, Bairro Tirirical \\ CEP 65055-970, São Luis - MA, Brasil \\ * Autor para correspondência \\ mayraaraguaia@hotmail.com
}

Submetido em 08/04/2013

Aceito para publicação em 22/06/2013

\section{Resumo}

O Felicola subrostratus tem sido descrito como ectoparasito específico de felinos, mas sua infestação é incomum. Este manuscrito relata a primeira ocorrência do malófago $F$. subrostratus parasitando gatos domésticos do município de São Luís do Maranhão, Brasil. Relatam-se sete casos da infestação sobre gatos domésticos adultos jovens (uma fêmea da raça Persa, duas fêmeas mestiças de Persa, três machos mestiços de persa e um macho sem raça definida), todos de pelagem negra, provenientes de uma mesma casa com acesso à rua. Os animais foram examinados e, observado a presença de ectoparasitos, que foram coletados e fixados em álcool $70^{\circ} \mathrm{GL}$, clarificados e montados entre lâminas e lamínulas para posterior identificação. Os animais foram acompanhados durante um mês sem nenhum tratamento para observar evolução da ectoparasitose. Dentro do período citado, todos os gatos machos apresentaram áreas extensas de alopecia e tricorrexia. Nas fêmeas, apenas a gata de raça Persa manifestou pequenas áreas de alopecia. Depois do período de acompanhamento se instituiu tratamento com amitraz (banho na concentração 5:1000), sem obter nenhuma melhora. Estabeleceu-se então tratamento com fipronil $(0,25 \mathrm{~g} / 100 \mathrm{~mL})$ que debelou a infestação com apenas uma aplicação. Seis meses após tratamento os pêlos voltaram ao normal. Este relato constitui o primeiro diagnostico de Felicola subrostratus no Estado do Maranhão com posterior recuperação.

Palavras-chave: Ectoparasitos; Felinos; Infestação

\section{Abstract}

Felicola subrostratus parasitizing domestic cats of São Luís, Maranhão, Brazil: case report. Felicola subrostratus has been described as a specific ectoparasite of cats, but infestation is unusual. This manuscript reports the first occurrence of chewing lice (Felicola subrostratus) parasitizing domestic cats from São Luís, Maranhão, Brazil. All animals were young adults (one purebred, Persian female; two crossbred, Persian females; three crossbred, Persian males; and one male, breed unknown) that had black fur, were from the same house, 
and had access to the street. During examination, the ectoparasites were found, collected, and fixed in ethanol $\left(70^{\circ} \mathrm{GL}\right)$. In the laboratory they were mounted on slides and identified. The animals were monitored for one month without any treatment in order to observe the evolution of skin disease. Within this time, all male cats had extensive areas of alopecia and brittle hair. For the females, only the purebred Persian had small areas of alopecia. After this period, the cats were treated with amitraz (in baths at a concentration of 5:1000), which resulted in no improvement. The cats were then treated with fipronil $(0.25 \mathrm{~g} / 100 \mathrm{~mL})$, which stopped the infestation after one application. Six months after the treatment, the pelage returned to normal. This report is the first diagnosis of Felicola subrostratus for the state of Maranhão, Brazil.

Key words: Cats; Ectoparasites; Infestation

\section{Introdução}

A literatura descreve mais de 4.900 espécies de piolhos nos mais diversos hospedeiros, mamíferos e aves. Esses parasitos evoluíram com seus hospedeiros estreitando relações filogenéticas entre si, tornandose importantes pelo fato de determinados gêneros estarem restritos a certas ordens e, por vezes estritos a determinadas espécies de hospedeiros (SERRAFREIRE; DE MELLO, 2006).

O Felicola subrostratus tem sido descrito como um ectoparasito específico de felinos, mas sua infestação é incomum. É um piolho com aparelho bucal mastigador, faz parte da família Trichodectidae e são cosmopolitas (URQUHART et al., 1998). Sua infestação pode ser assintomática ou causar prurido intenso, ocasionando dermatite e perda de pêlos. Este piolho tem sido descrito como a única espécie de interesse médico veterinário que comumente parasita gatos domésticos, sendo os animais de pêlos longos os mais severamente atacados (AHID, 2009).

Os animais atingidos e todos aqueles da mesma espécie que tiverem contato com o animal infectado devem ser tratados. Com limpeza das camas e do ambiente, por apenas uma vez, visto que os piolhos não sobrevivem mais que dois dias fora do hospedeiro (MEDLEAU; HNILICA, 2003). Se o animal estiver com os pêlos emaranhados, é preciso fazer a tosa. Tosar os animais infestados é muito útil para reduzir a carga de ovos, bem como de adultos e permitir o uso efetivo das terapias tópicas (CHANDLER et al., 2006).

Este trabalho relata pela primeira vez infestação por F. subrostratus em gatos domésticos de São Luís, Maranhão, Brasil.

\section{Materiais e Métodos}

Foi examinado um grupo de doze gatos que viviam em uma casa com acesso à rua, de um bairro central do Município de São Luís, Estado do Maranhão, formado por sete gatos de pelagem negra e cinco de pelagem clara. Os gatos de pelagem negra eram adultos de diferentes raças (uma fêmea da raça Persa, duas fêmeas mestiças de Persa, três machos mestiços de Persa castrados e um macho sem raça definida). Constatou-se que estes animais apresentavam prurido intenso e pontinhos brancos nos pêlos, semelhantes a grãos de areia. Ao exame clínico, observaram-se ectoparasitos em todos os gatos de pelagem negra, ao passo que nos de pelagem clara não foi constatado nenhum parasito.

Os espécimes foram coletados manualmente junto com o pêlo, pois este se destacava com um leve puxar, e armazenados em álcool $70^{\circ} \mathrm{GL}$. Realizou-se também o raspado de pele nas áreas com alopecia para pesquisa microbiológica, de fungo ou bactéria. Os malófagos foram identificados ao exame microscópico após a clarificação em solução de potassa $10 \%$ por 30 min e em fenol, até se obter a clarificação ideal, logo em seguida os espécimes foram colocados no creosoto para completar a diafanização. A seguir, os ectoparasitos foram para a montagem definitiva com o Bálsamo do Canadá e entre lâmina e lamínula.

\section{Resultados e Discussão}

Um aspecto relevante dos parasitas de felinos é o problema que representam como zoonoses, podendo oferecer risco de contaminação às pessoas que entram em contato com esses animais (CHANDLER et al., 2006). 
Comprovou-se apenas a infestação por $F$. subrostratus (Figura 1a) e optou-se em acompanhar a evolução da infestação somente a título de se avaliar a evolução da dermatose. No período de um mês, todos os machos apresentavam áreas extensas de alopecia e tricorrexia (Figura 1b). E das fềmeas, apenas a da raça Persa manifestou pequenas áreas de alopecia no ventre e lateral do corpo.

Ao término do período de acompanhamento, iniciou-se o tratamento com amitraz (Triatox ${ }^{\circledR}$ ) formulação de banho diluição de 5:1000 (v/v), uma vez por semana, por duas semanas consecutivas sem obter nenhuma melhora e com expansão das áreas de alopecia. Estabeleceu-se então o tratamento com fipronil (Frontline ${ }^{\circledR}$ Spray), concentração de 0,25 g/100 mL, o que debelou a infestação com apenas uma aplicação em todos os animais. Para o tratamento efetivo incluindo a morte dos ovos, indicou-se terapia durante cinco semanas consecutivas.

Os pêlos que nasceram nas áreas afetadas continuavam com tricorrexia e despigmentados (Figura 2a). Somente seis meses após o tratamento os pêlos voltaram a ter resistência e pigmentação normais (Figura $2 b$ ).

O piolho F. subrostratus tem sido descrito em infestações mistas com outros ectoparasitos como Lynxacarus radovskyi (AGUIAR et al., 2009) e Demodex sp. (PEREIRA et al., 2005). Trata-se de parasitose que na maioria das vezes é assintomática e de fácil diagnóstico e tratamento. Apesar de não ser conhecido nenhum patógeno transmitido por esse malófago, por não ser hematófago, o animal acometido se torna irritadiço pelo incômodo provocado pelo prurido e, além disso, fica

FIGURA 1: a - Felicola subrostratus (Burmeister, 1838), armadura bucal (seta); b - Gato macho, SRD, com extensa área de alopecia.
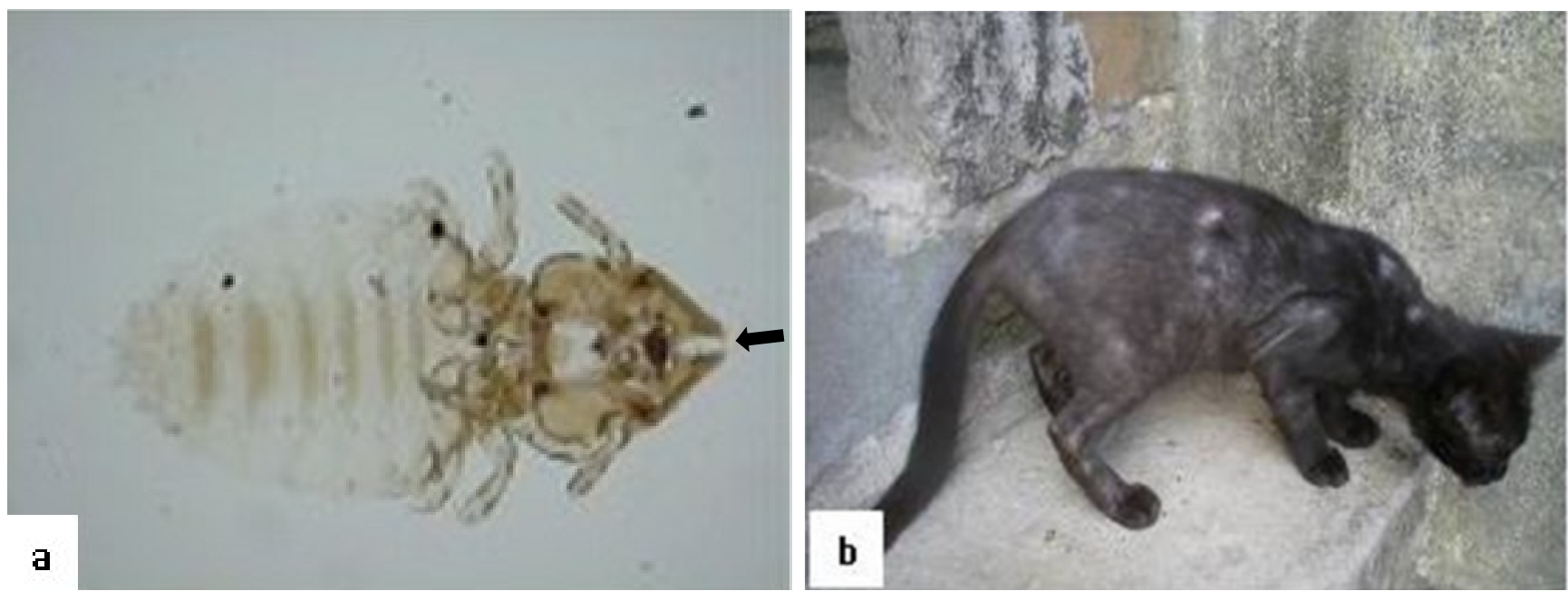

FIGURA 2: a - Estrutura do pêlo pós-tratamento: seta (tricorrexia e despigmentação). b - integridade e uniformidade dos pelos após seis meses de tratamento.
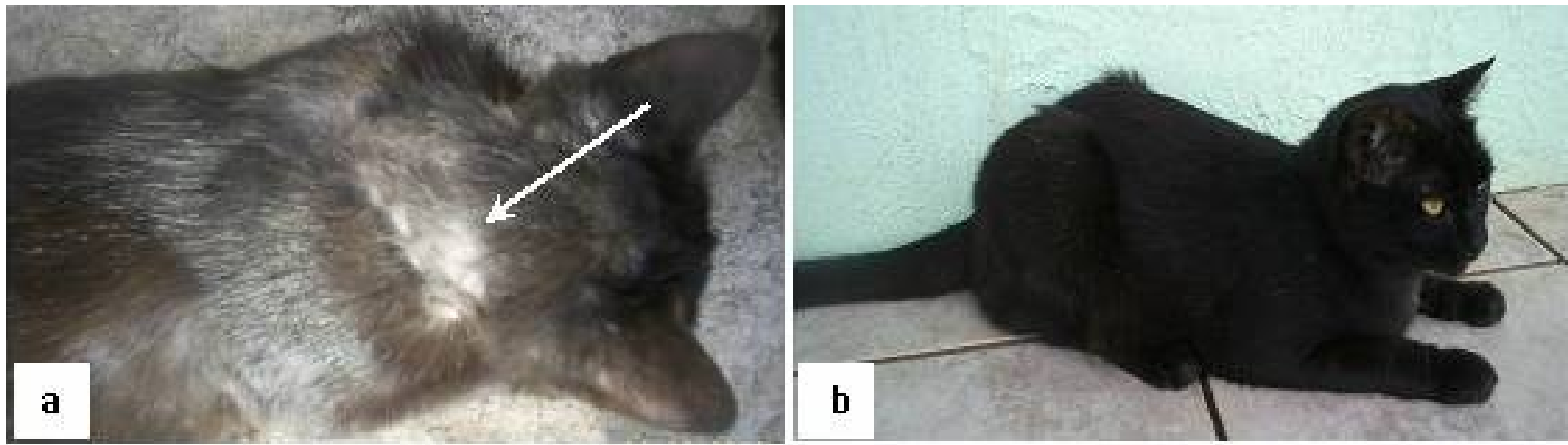
com aparência de animal abandonado devido à alopecia (PERDOMO; FUENTES, 2003).

O F. subrostratus não é comum, embora apresente distribuição geográfica mundial. Todavia a ocorrência de várias infestações é bem documentada em museus (RÉKÁSI, 1979). Outros relatos recentes sugerem que a infestação provocada por este parasito está relacionada ao manejo inadequado dos gatos (CANESTRI-TROTTI et al., 1990; RASCHKA et al., 1994; RATAJ et al., 2004; 'ZIVI`CNJAK et al., 2007; INGSTRUP, 2008; KNAUS et al., 2011; CAPARI et al., 2013).

Em estudos recentes como os realizados na cidade de São Luís por Chaves et al. (2004), analisando ectoparasitos de gatos domésticos e Figueiredo et al. (2010) estudando felídeos silvestres não noticiaram a presença de piolhos sobre os animais estudados e por isso inferiram que a infestação por este parasito não era comum.

Segundo Rey (2001), as infestações por piolhos são mais frequentes em animais subnutridos, diferente do que foi observado no presente estudo, já que, em que pese a presença da infestação, os animais apresentavam bom estado geral o que corrobora os achados de Silva (2011), em que todos os animais parasitados, apresentavam bom estado físico, e se encontravam no peso adequado para a idade e o sexo. Além disso, todos os animais acometidos eram de pelagem negra, da mesma forma como os achados de Silva (2011), sugerindo certa predisposição da cor da pelagem para a infestação por piolhos, embora na literatura não seja descrita esta característica.

Também foram observados alopecia e prurido intenso em todos os machos e na fêmea da raça Persa, concordando com o relato de Scott et al. (1996) que relata que a infestação por piolhos pode ser assintomática ou apresentar prurido variado, e que animais sensíveis podem apresentar prurido intenso e dermatites graves, chegando a alopecia, propiciando infecções bacterianas secundárias.

A atenção clínica sobre ectoparasitoses em felinos deve ser mantida, mesmo que de rara ocorrência, as manifestações clínicas podem ser confundidas com outras dermatopatias.
Este é o primeiro relato de gatos domésticos parasitados por F. subrostratus no Município de São Luís do Maranhão e vem contribuir com informações sobre a fauna parasitária dos animais domésticos e com o tratamento das ectoparasitoses dos mesmos.

\section{Referências}

AGUIAR, J.; MACHADO, M. L. S.; FERREIRA, R. R.; HÜNNING, P. S.; MUSCHNER, A. C.; RAMOS, R. Z. Infestação mista por Lynxacarus radovskyi e Felicola subrostratus em um gato na região de Porto Alegre, RS, Brasil. Acta Scientiae Veterinariae, Porto Alegre, v. 37, n. 3, p. 301-305, 2009.

AHID, S. M. M. Apostila didática em Entomologia Veterinária. Mossoró: UFERSA, 2009. 80 p.

CANESTRI TROTTI, G.; CORRADINI, L.; VISCONTI, $\mathrm{S}$. Indagine parassitologica in un rifugio per gatti a Ferrara. Parassitologia, Roma, v. 32 (Supplemento 1), p. 42-43, 1990.

CAPARI, B.; HAMELC, D.; VISSER, M.; WINTER, R.; PFISTER, K.; REHBEIN, S. Parasitic infections of domestic cats, Felis catus, in western Hungary. Veterinary Parasitology, Amsterdam, v. 192, p. 33-42, 2013.

CHANDLER, E. A.; GASKELL, C. J.; GASKELL, R. M. Clínica e terapêutica em felinos. 3 ed. São Paulo: Roca, 2006. 590 p.

CHAVES, E. P.; FEITOSA, M. L. T.; FRASSON, L. R.; GUERRA, R. M. S. N. C.; SANTOS, A. C. G.; SANTOS-RIBEIRO, A. Prevalência de ectoparasitos em gatos domésticos (Felis catus) na cidade de São Luís-MA. Revista Brasileira de Parasitologia Veterinária, São Carlos, v. 23, n. 1, p. 348, 2004.

FIGUEIREDO, M. A. P.; SANTOS, A. C. G.; GUERRA, R. M. S. N. C. Ectoparasitos de animais silvestres no Maranhão. Pesquisa Veterinária Brasileira, Seropédica, v. 30, n. 11, p. 988-990, 2010. INGSTRUP, A. 2008. Parasitter hos danske katte - en prævalensundersøgelse af 719 internatkatte. Copenhagen: Hovedopgave ved Fagdyrlægekursus i sygdomme hos hund \& kat. Disponível em <www.ddd.dk/../2009-01\%20Astrid\%20Ingstrup. pdf>. Acesso em: 21 março 2013.

KNAUS, M.; RAPTI, D.; KUSI, I.; SHUKULLARI, E.; POSTOLI, R.; XHAXHIU, D.; WINTER, R.; VISSER, M.; REHBEIN, S. Survey of endo- and ectoparasites of cats from Tirana, Albania. In: INTERNATIONAL CONFERENCE OF THE WORLD ASSOCIATION FOR THE ADVANCEMENT OF VETERINARY PARASITOLOGY, 23, 2011, Buenos Aires. Proceedings... Buenos Aires: WAAVP, 2011. p. 232.

MEDLEAU, L.; HNILICA, K. A. Dermatologia de pequenos animais: atlas colorido e guia terapêutico. 1 ed. São Paulo: Roca, 2003. 353 p.

PERDOMO, L.; FUENTES, O. Felicola subrostratus en los gatos domésticos de Cuba. Revista de Salud Animal, La Habana, v. 25, n. 2, p.126-128, 2003.

PEREIRA, S. A.; SCHUBACH, T. M. P.; FIGUEIREDO, F. B.; LEME, L. R. P.; SANTOS, L. B.; OKAMOTO, T.; CUZZI, T.; REIS, R. S.; SCHUBACH, A. Demodicose associada à esporotricose e pediculose em gato co-infectado por FIV/FeLV. Acta Scientiae Veterinariae, Porto Alegre, v. 33, n. 1, p. 75-78, 2005. 
RASCHKA, C.; RIBBECK, R.; HAUPT, W. Untersuchungen zum Ektoparasitenbefall bei streunenden Katzen. Monatschefte für Veterinärmedizin, Leipzig, v. 49, p. 257-261, 1994.

RATAJ, V. A.; POSEDI, J.; BIDOVEC, A. Ectoparasites: Otodectes cynotis, Felicola subrostratus and Notoedres cati in the ear of cats. Slovenian Veterinary Research, Ljubljana, v. 41, p. 89-92, 2004.

RÉKÁSI, J. Die Federling-Sammlung des Ungarischen Naturwissenschaftlichen Museums, II. Parasitologia Hungarica, Budapest, v. 12, p. 93-98, 1979.

REY, L. Parasitologia - Parasitos e doenças parasitárias do homem nas Américas e na África. 2 ed. Rio de Janeiro: Guanabara Koogan, 2001. $731 \mathrm{p}$.

SCOTT, D. W.; MILlER, H. W.; GRIFFIN, C. E. Doenças parasitárias da pele. In: MULLER, E.; KIRK, E. (Ed.). Dermatologia dos pequenos animais. 5. ed. São Paulo: Manole, 1996. p. 374-376.
SERRA-FREIRE, N. M.; MELLO, R. P. Entomologia \& Acarologia na Medicina Veterinária. 1. ed. Rio de Janeiro: L. F. Livros, 2006. 199 p.

SILVA, A. O. Incidência de ectoparasitos encontrados em gatos (Felis silvestris catus) no município de Manaus, AM. 2011. 69 f. Trabalho de Conclusão de Curso (Bacharelado em Medicina Veterinária) - Escola Superior Batista do Amazonas, Manaus. 2011. URQUHART, G. M.; ARMOUR, J.; DUNCAN, J. L.; DUNN, A. M.; JENNINGS, F. W. Parasitologia veterinária. 2. ed. Rio de Janeiro, Guanabara Koogan, 1998. 304 p.

`ZIVI ${ }^{` C N J A K, ~ T . ; ~ S T O J ~}{ }^{` C E V I, ~ C . ~ D . ; ~ M A R I N C U L I, ~ C . ~ A . ; ~}$ BECK, R.; VECL, L. Dermatitisi i ektoparaziti kod ku'cnih ljubimaca: na`sa iskustva. In: CVRTILA, `Z.; KONJEVI, C. D. (Ed.). Zbornik sǎzetaka znanstveno strǔcnog sastanka "Veterinarska znanosti i struka". Zagreb: Veterinarska fakultet Sveu cilǐsta u Zagrebu, 2007. p. 50. 